\title{
A tale of two tails: a rare occurrence of tail bifurcation in the red-backed salamander (Plethodon cinereus)
}

\author{
ERIC B. LIEBGOLD
}

\author{
Department of Biological Sciences, Salisbury University, Salisbury, Maryland 21801, USA \\ Author e-mail: ebliebgold@salisbury.edu
}

$T_{\mathrm{a}}^{\mathrm{a}}$ ail bifurcation, in which the tail duplicates after mechanical damage, is a rare event in the wild that has been reported in some Squamata (Kornilev et al., 2018) and Urodela (reviewed in Henle et al., 2012; Romano et al., 2017). This condition can be replicated experimentally by inflicting irregular damage to the tail including partial spinal cord removal (Dawson, 1932). Despite plethodontids being the most abundant vertebrates in eastern North America (Burton \& Likens, 1975), tail bifurcation has only been reported in plethodontids twice in the last 113 years, both times in the common and abundant Plethodon cinereus (Blatchley, 1906; Lynn, 1950). On 31 May 2008 at 15:35 h, I found an adult female $P$. cinereus with a bifurcated tail (Fig. 1) under a rock near Spring Road at Mountain Lake Biological Station, Giles County, Virginia, USA ( $\left.37^{\circ} 22^{\prime} 12.97^{\prime \prime} \mathrm{N}, 80^{\circ} 31^{\prime} 14.92^{\prime \prime} \mathrm{W}\right)$ during collection of this species for an experiment (Liebgold \& Dibble, 2011). The salamander was brought into the laboratory, measured (snout-vent length $=38.88 \mathrm{~mm}$, longest tail length $=29.83$ $\mathrm{mm}$, tail length past the point of bifurcation: main tail $=22.68$ $\mathrm{mm}$; supernumerary tail $=12.85 \mathrm{~mm}$ ), and then released at the point of capture within $24 \mathrm{~h}$. Lynn (1950) described an individual of $P$. cinereus with a dorsal-ventral tail bifurcation and found red pigment was present only on the dorsal tail. In contrast, the individual presented here had a lateral tail bifurcation, with red dorsal pigment present on both tails (Fig. 1). Both tails had regenerating tips, which indicates that tail autotomy had occurred within the few weeks prior to collection. This demonstrates that, after tail bifurcation, autotomy and regrowth can occur in both the main and supernumerary tails.

Little information is available about the frequency of tail bifurcation in amphibians due to the scarcity of data on the number of normal individuals in any particular population. However, in a detailed review, Henle et al. (2012) quoted two examples of bifurcation rate, Triturus cartifex 1:48 (2.08\%) and Ambystoma talpoideum 1:17,935 (0.006 \%); on the two previous occasions when tail bifurcation was reported in $P$. cinereus there was no information on frequency (IndianaBlatchley, 1906; Massachusetts- Lynn, 1950). At Mountain Lake Biological Station and in the surrounding Jefferson National Forest, Virginia, USA, P. cinereus is abundant, with densities of $0.97-6.30 / \mathrm{m}^{2}$. From 2005-2009, a colleague (T. Ransom) and I collected 1942 different individuals of $P$. cinereus for studies that were published from 2006-2017 (including the collection during which this individual was

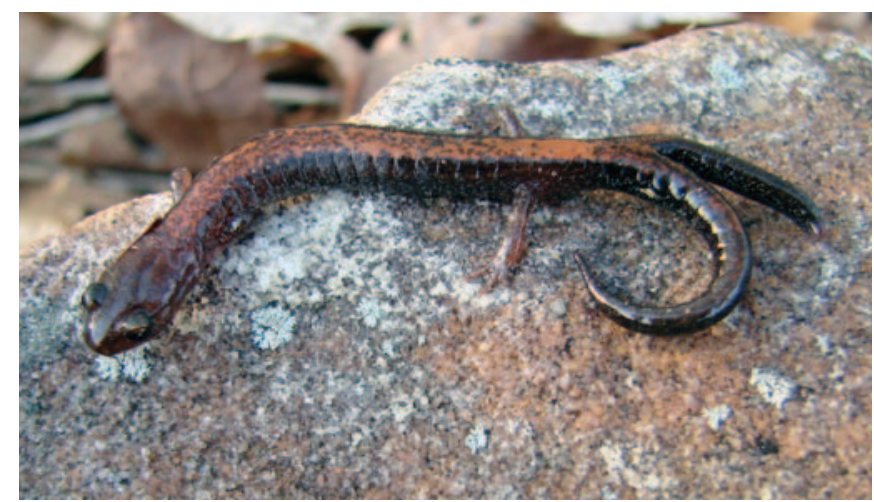

Figure 1. Female $P$. cinereus with a bifurcated tail captured on 31 May 2008 at Mountain Lake Biological Station, Virginia, USA

found but not used: Liebgold \& Dibble, 2011). Individuals were marked with visible implant elastomer (Northwest Marine Technology Inc., Shaw Island, WA) so they were not used in multiple experiments or individuals were collected from areas that were not revisited. None of the other 1941 individuals collected had bifurcated tails. Our estimate of the frequency of tail bifurcation in $P$. cinereus in this area was therefore 1:1942 (0.05\%).

\section{ACKNOWLEDGEMENTS}

Data was collected under Virginia Department of Game and Inland Fisheries permit \#030986 and ACUC Protocol No. 3581, which was approved by the UVA Animal Care and Use Committee. I thank Mountain Lake Biological Station for permission to conduct field work.

\section{REFERENCES}

Blatchley, W.S. (1906). On some reptilian freaks from Indiana. Proceedings of the Academy of National Sciences Philadelphia 58: 419-422.

Dawson, A.B. (1932). A ventral accessory tail in Triturus viridescens and its duplication experimentally. Anatomical Record 52: 139-149.

Henle, K., Mester, B., Lengyel, S. \& Puky, M. (2012). A review of a rare type of anomaly in amphibians, tail duplication and bifurcation, with description of three new cases in European species (Triturus dobrogicus, Triturus carnifex, and Hyla arborea). Journal of Herpetology 46: 451-455. 
Kornilev, Y.V., Popgeorgiev, G., Vacheva, E. \& Tzankov, N. (2018). First records of melanism (including in tail bifurcation) of lacertid lizards (Reptilia: Lacertidae) in Bulgaria. North-Western Journal of Zoology 14: 142-144. Liebgold, E.B. \& Dibble, C.J. (2011). Better the devil you know: familiarity affects foraging activity of red-backed salamanders, Plethodon cinereus. Animal Behaviour 82: 1059-1066.
Lynn, W.G. (1950). A case of duplication of the tail in Plethodon. Herpetologica 6: 82-84.

Romano, A., Avella, I. \& Roger, D.S. (2017). Body malformations in a forest-dwelling salamander, Salamandrina perspicillata (Savi, 1821). Herpetological Conservation and Biology 12: 16-23. 